\title{
Markets for technology in the knowledge economy
}

\author{
Ashish Arora, Andrea Fosfuri, and Alfonso Gambardella
}

\section{Introduction}

It is now a commonplace that we live in the knowledge economy. Like all cliches, this one too is wrong insofar as it suggests that earlier economies did not rely upon knowledge. If there is something different about the economic system that has characterised the majority of industrialised countries over the last two and a half centuries, it is arguably the increased importance of scientific and technological knowledge for economic activity. No less an economist than Simon Kuznets himself argued that the distinguishing characteristic of modern economic growth has been the systematic application of science to economic ends. Indeed, we submit that what distinguishes the so-called "knowledge economy" from earlier eras is the increasing role of knowledge as an economic commodity, bought and sold in markets for technology.

This article draws upon a long-standing study carried out by the authors for quite a few years, and recently published in a book (Arora et al. 2001a). The focus of this research has been the study of the nature and functioning of markets for technology,
Ashish Arora is associate professor at the Heinz School of Public Policy and Management, Carnegie Mellon University, Pittsburgh, where he is research director of the Carnegie Mellon University Software Industry Center.

Email: ashish@andrew.cmu.edu

Andrea Fosfuri is assistant professor of strategic management at the Business Department of the University Carlos III, Madrid, and Research Affiliate at CEPR, London, UK.

Email: fosfuri@emp.uc3m.es

Alfonso Gambardella is professor of economics and management at the Sant'Anna School of Advanced Studies, Pisa, Italy.

Email: gambardella@sssup.it

All three have published in leading economics and management journals, and together were co-authors of Markets for Technology: The Economics of Innovation and Corporate Strategy (2001). Arora also co-edited Chemicals and Long Term Economic Growth. Gambardella also authored of Science and Innovation (1995), and co-edited The Organization of the Innovative Activity in Europe, Cambridge University Press, 1999.
(1990). For Chandler, the systematic application of science takes place within the more organised confines of the firm, as the production of new knowledge is combined with its application through mutually complementary investments in research, manufacturing, and marketing.

This vision of knowledge creation integrated with knowledge use has become inadequate for understanding economic growth in the twenty-first century. Over the past 10 to 15 years, there has been a rapid growth in a variety of arrangements for the exchange of technologies or technological services, ranging from $\mathrm{R} \& \mathrm{D}$ joint ventures and partnerships, to licensing and crosslicensing agreements, to contracted R\&D. 
Although we lack comprehensive empirical measures of the increase in such arrangements over time, all the available evidence suggests that the trade in technologies is more common than it was in the past. For instance, Grindley and Teece (1997) point to the increasing use of technology licensing by companies such as IBM, Hewlett-Packard, Texas Instruments, and AT\&T during the 1990s. Moreover, today, a number of firms and software products have emerged to help firms manage their patent portfolios. Firms specialising in the creation of new technology are now an important part of the industrial landscape in many technology-intensive industries. Finally, we have seen the development of electronic and online market places where technologies can be bought and sold.

We are not suggesting that in-house R\&D in well-known corporations will be supplanted by externally conducted R\&D. Rather, we are trying to understand the conditions under which technology can be traded, be it by established firms or by firms specialising in the production of technology. In addition to the diffusion of technology, such transactions could play an important role in fostering innovation. This is the case when the developers of the technology lack the resources necessary to commercialise it. Without the prospect of being able to capitalise on their innovations by trading them, many small technology-based firms would not invest in creating new and useful technologies. Moreover, as we shall argue here, international markets for technology can be an important mechanism for an effective diffusion of technology in the developing countries.

We begin with a tentative definition of markets for technology and by summarising the empirical evidence on the size and importance of these markets. Section 3 focuses on the implications of the development of technology markets for corporate strategy. Section 4 deals with the role of markets for technology in fostering the international diffusion of technology. Section 5 concludes by discussing national policy implications in light of the globalisation of these markets.

\section{Markets for technology}

\section{A tentative definition}

In this paper we use the term "market" in a broad sense. Strictly speaking, market transactions are arm's length, anonymous, and typically involve an exchange of a good for money. Many, if not most, transactions for technology which we have observed would fail one or the other criterion. Often they involve quite detailed contracts and may be embedded in technological alliances of some sort. Thus, though we shall often paint with a broad brush, contrasting market transactions with processes inside a firm, it is not to dispute the existence of hybrid forms that characterise market transactions in technology but rather to sharpen the exposition.

Technology comes in very different forms, and no general definition will fit. For instance, technology can take the form of "intellectual property" (patents) or intangibles (e.g., a software program, or a design), or it can be embodied in a product (e.g., a prototype, or a device like a chip designed to perform certain operations), or it can take the form of technical services. We will not attempt to define technology, treating it instead as an imprecise term for useful knowledge rooted in engineering and scientific disciplines, which usually also draws from practical experience from production. In turn, this means that technology transactions can take different forms, from pure licensing of well-defined intellectual property, to complicated collaborative agreements which may well include the further development of the technology, or its realisation "from scratch". ${ }^{1}$ Table 1 summarises our definition of the market for technology in the form of a simple typology, along with canonical examples for each case.

Our definition of the market for technology is close to the one proposed by the US Dept. of Justice in its Antitrust Guidelines for the Licensing of Intellectual Property (US Dept. of Justice 1995). The US Dept. of Justice defines markets for technology as markets for "intellectual property that is licensed and its close substitutes - that is the technologies or goods that are close enough substitutes significantly to constrain the exercise of market power with respect to the intellectual property that is licensed" (US Dept. of Justice 1995, p. 6). Our definition in 


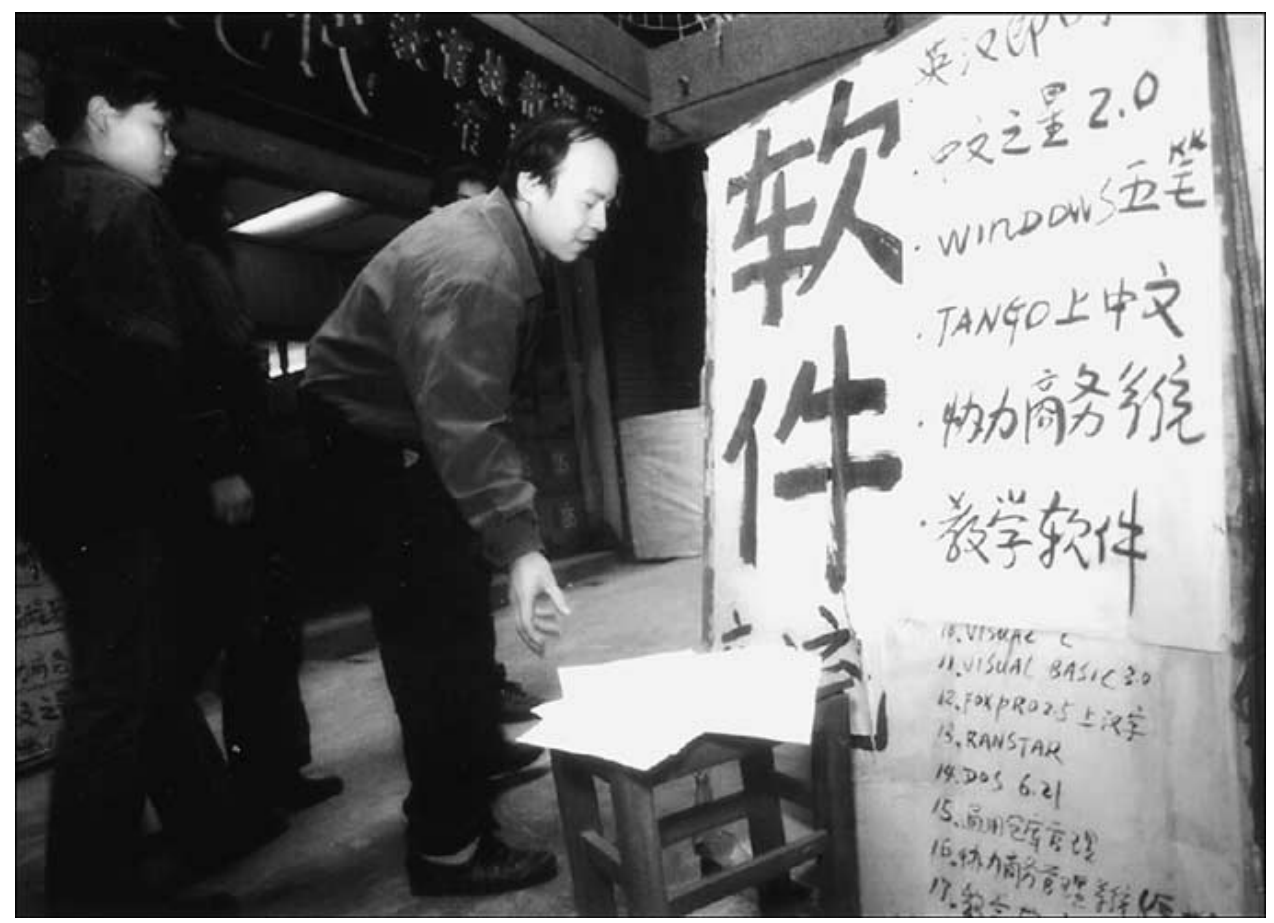

Selling software in Guangzhou, China, 2001. Richard Jones/SINOPIX-REA

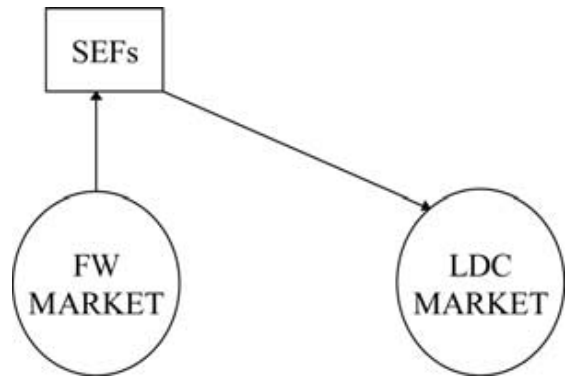

FIGURE 1. The transmission of growth impulses.

Table 1 also encompasses what the Dept. of Justice calls "markets for innovation", which are seen as markets for "futures" technologies. These include arrangements in which the parties agree to conduct activities, jointly or indepen- dently, leading to future developments of technologies that will be exchanged (or jointly owned) among them. This is typically the market for contract $R \& D$ and the various types of technological alliances and joint-ventures.

In sum, a market for technology refers to transactions for the use, diffusion, and creation of technology. This includes transactions involving full technology packages (patents and other intellectual property and know-how) and patent licensing. It also includes transactions involving knowledge that is not patentable or not patented (e.g., software, or the many nonpatented designs and innovations).

\section{Some suggestive evidence}

Markets for technology are not new. Lamoreaux and Sokoloff $(1997,1999)$ have documented the existence of an active market for patents in the 
TABLE 1. A simple typology of markets for technology

\begin{tabular}{lll}
\hline & Existing technology & Future technology or component for future \\
\hline $\begin{array}{l}\text { Horizontal market/transactions } \\
\text { with actual or potential rivals }\end{array}$ & $\begin{array}{l}\text { Union Carbide licensing Unipol } \\
\text { polyethylene technology to } \\
\text { Huntsman Chemicals }\end{array}$ & $\begin{array}{l}\text { Sun licensing Java to IBM; R\&D joint } \\
\text { ventures or other technological alliances } \\
\text { between rivals }\end{array}$ \\
$\begin{array}{l}\text { Vertical market/Licensing } \\
\text { to non-rivals }\end{array}$ & $\begin{array}{l}\text { Licensing of IP Core in } \\
\text { semiconductors }\end{array}$ & $\begin{array}{l}\text { R\&D joint ventures or other technological } \\
\text { alliances; Affymax licensing combinatorial } \\
\text { drug discovery technology to pharmaceutical } \\
\text { companies }\end{array}$ \\
\hline
\end{tabular}

US during the nineteenth century. However, it appears that these markets declined after the 1920 s, and have become reinvigorated only in the last couple of decades. ${ }^{2}$ In Arora et al. (2001a) we provide rough estimates of the size and scope of markets for technology for recent decades. Using systematic data on technology transactions we found that the extent of technology trade has grown in the 1990s, and hightech industries like software, chemicals, and electronics lead the growth of such markets. Table 2 shows the total number and, in parentheses, the value of such transactions, by industrial sector, between 1985 and 1997. The value of a transaction is calculated here as the sum of licensing and royalty payments, and equity investments and $R \& D$ funding provided in return for licensing rights.

Table 2 shows that there have been over 15,000 transactions in technology with a total value of over $\$ 330$ billion, implying an average of nearly 1,150 transactions worth $\$ 27$ billion per year. ${ }^{3}$ Using data on royalty payments received by U.S. firms, one arrives at a similar estimate for the size of technology markets. This consistency is reassuring and suggests that the total volume of technology transactions is of the order of $\$ 30-\$ 50$ billion per year. To put these numbers in perspective, note that the total R\&D spending in the US, Japan, Germany,

TABLE 2. The market for technology: number and value (millions of 1995 dollars) of technology transactions, 1985-97, by sector

\begin{tabular}{lccccccccccc}
\hline & $1985-89$ & 1990 & 1991 & 1992 & 1993 & 1994 & 1995 & 1996 & $\begin{array}{c}1997 \\
\text { Total number } \\
\text { (total value) }\end{array}$ \\
\hline SIC28 & 439 & 310 & 461 & 395 & 486 & 596 & 351 & 208 & 222 & 3496 \\
& $(5809)$ & $(4102)$ & $(6101)$ & $(5227)$ & $(6431)$ & $(7887)$ & $(4645)$ & $(2753)$ & $(2938)$ & $(46,264)$ \\
SIC35 & 129 & 115 & 210 & 188 & 195 & 192 & 164 & 63 & 69 & 1360 \\
& $(6280)$ & $(5599)$ & $(10,224)$ & $(9153)$ & $(9493)$ & $(9347)$ & $(7984)$ & $(3067)$ & $(3359)$ & $(66,211)$ \\
SIC36 & 234 & 190 & 310 & 316 & 366 & 415 & 326 & 135 & 151 & 2479 \\
& $(10,971)$ & $(8908)$ & $(14,534)$ & $(14,816)$ & $(17,160)$ & $(19,457)$ & $(15,284)$ & $(6329)$ & $(7080)$ & $(116,227)$ \\
SIC73 & 143 & 207 & 360 & 334 & 363 & 610 & 770 & 405 & 424 & 3689 \\
& $(1740)$ & $(2518)$ & $(4380)$ & $(4063)$ & $(4416)$ & $(7421)$ & $(9368)$ & $(4927)$ & $(5158)$ & $(44,881)$ \\
SIC87 & 11 & 9 & 45 & 253 & 156 & 73 & 34 & 22 & 17 & 707 \\
All & $(171)$ & $(140)$ & $(701)$ & $(3939)$ & $(2429)$ & $(1137)$ & $(529)$ & $(343)$ & $(265)$ & $(11,009)$ \\
others & 174 & 209 & 468 & 523 & 560 & 540 & 545 & 289 & 293 & 3858 \\
Total & 1130 & 1040 & 1854 & 2009 & 2126 & 2426 & 2190 & 1122 & 1176 & 15073 \\
& $(27,753)$ & $(24,169)$ & $(41,410)$ & $(43,571)$ & $(46,479)$ & $(51,604)$ & $(44,469)$ & $(20,761)$ & $(21,956)$ & $(332,831)$ \\
\hline
\end{tabular}

Note: SIC28 = Chemicals; SIC35 = Industrial Machinery and Equipment; SIC36 = Electronic and Other Electrical Equipment; SIC73 = Business Services; SIC87 = Engineering and Management Services.

Source: The data are from a commercial database provided by the Securities Data Corporation, the leading commercial provider of such data. For more details see Arora et al. (2001a). 
UK, France, Italy, and Canada was about $\$ 340$ billion, and non-defence R\&D spending was about $\$ 300$ billion in 1995 . Thus, the value of the total technology transactions is about $9 \%$ of total non-defence $\mathrm{R} \& \mathrm{D}$ spending in the developed countries. Although markets for technology are still in their infancy in many cases, the value of the transactions is already substantial. Our data also show, that the number of these transactions has been steadily increasing over time, with the exception of the last two years in our sample (possibly reflecting incomplete reporting of transactions for these years).

Specific industry case-studies provide possibly the most compelling evidence of the increasing importance of technology markets. The chemical industry for instance is one in which licensing of both product and process technology has been widespread for many years. Similarly, technology trade is becoming extensive in leading high-tech industries such as software, semiconductors, and biotechnology. For instance, in semiconductors there has been a significant growth of the so-called "fabless" or even "chipless" companies, which specialise in the design of self-contained, independent chip "modules" and sell their designs to other companies that design and manufacture the complex chip in which the individual modules are embedded. In addition, during the last decade both licensing and cross-licensing deals have risen significantly in this industry and the propensity to patent has increased in response to the greater need to protect intellectual property in such deals. ${ }^{4}$

\section{Markets for technology and corporate strategy}

\section{The effects of "missing" markets for corporate assets}

In order to understand the implications of markets for technology, it is useful to begin with a more general discussion of missing markets for assets that distinguish a firm from its competitors. These assets include technology, production expertise and facilities, strong brandname reputation, human assets, supplier networks and established marketing channels. To be a source of sustained above-average perform- ance, resources must meet three criteria: they must be valuable, scarce, and imperfectly mobile (see Barney 1991). In other words, a competitive advantage must be underpinned by resources for which well-functioning markets do not or cannot exist. So, the firm builds a sustainable competitive advantage by having access to assets that its competitors cannot reach. Similarly, much of the thinking on technology strategy has approached the problem by implicitly or explicitly assuming that technological assets cannot be directly bought and sold, and the services of such assets cannot be "rented".

What are the consequences of such a missing market for technology? The immediate consequence is that the innovator must exploit the technology in-house. That is, in order to extract the value from the technology, it (or rather its services) must be embodied in goods and services which are then sold. Such goods and services must have lower costs or command higher prices, to deliver returns that are greater than the competitive rate of returns.

Consider a case where a firm has developed a new cost-reducing technology for the production of a certain good. In order to extract value from the technology, the firm must use it to produce the good. Not only does this require the firm to have access to the complementary assets (such as land and physical equipment, marketing channels, and so on), but the returns would also depend on the volume of output that the firm can produce and sell. If the complementary assets are themselves not traded in a competitive market, or if firms differ in their access to them, then firms that have superior access to these complementary assets will be able to derive greater value from the technology. Similarly, firms that can exploit the technology on a bigger scale will be able to derive greater value.

Following this logic further, larger firms or firms with superior access to complementary assets will have a greater incentive to invest in the technology in the first instance. Taking this one step further, firms investing in technology would be well advised to also invest in the complementary assets that cannot be easily and efficiently acquired from the market. In other words, as Teece (1986) put it, firms have to invest in creating co-specialised assets to maximise their returns from developing new tech- 
nology. In sum, absent a market for technology, a firm must often acquire other assets in order to extract profits from the technology. Insofar as these other assets are themselves expensive and illiquid, well capitalised, large, integrated firms that possess such assets have greater incentives to invest in developing new technologies (Nelson 1959). Conversely, smaller firms face major hurdles in developing and commercialising technology.

The situation is quite different when the asset can be sold or rented. Complementary assets need not be owned or even directly accessed by the technology developer. The relative importance of complementary assets within the boundaries of the individual firms diminishes compared to the existence of such complementary assets at the level of industries or markets as a whole. Clearly transaction costs or factors may increase the cost of acquiring the complementary assets externally compared to owning them in-house, even when such markets exist. In our book, we distinguish between cognitive factors (such as context dependence and absorptive capacity), contractual problems and other market imperfections that can limit the ability of firms to access external complementary assets. As these imperfections become less important, then, to use Teece's terminology, the existence of complementary assets at the level of markets or industries may offset the lack of such assets at the level of the firm.

Ultimately, a market for the asset provides the innovator - a firm that has developed new technology - with more options. Instead of embodying a newly developed technology in goods and services, a firm may choose to sell or license it to others, or it may choose to buy it from external providers rather than develop it in-house. This does not mean that companies would only acquire technologies from external sources. Leading companies would probably choose the right balance between external acquisition and in-house development of technologies, even though for companies with lower in-house technological capabilities the existence of external technology sources may be critical to enhance their ability to produce and sell more innovative goods. Similarly, a market for technology assets does not mean that innovating firms will become pure licensing companies, although several small (and not so small) firms have been successful as specialised technology suppliers. Rather, as we shall also note below, the appropriate strategy in the presence of markets for technology depends on the efficiency of markets for other types of assets, including finance.

Moreover, in thinking about how a market for technology conditions strategy, there is one other industry level force that must be considered. Markets, particularly efficient markets, are great levelers. A market for technology lowers entry barriers and increases competition in the product market, which often implies a rethink of existing strategies. In turn, this implies that when there exists a well-functioning market for an asset, such an asset cannot be a source of sustainable competitive advantage and firms have to look somewhere else for gaining an edge over competitors.

\section{Markets for technology and strategies for appropriating rents}

Teece (1986) identifies several factors that determine a firm's ability to appropriate returns from an innovation: nature of technology, strength of the intellectual property rights regime, complementary assets, ease of replication, and ease of imitation. Appropriation through licensing works best when a substantial gap exists between replication and imitation costs. If the technology is easy to replicate and transfer but difficult to imitate, the innovator can capture a large part of the rents simply by licensing. Hence, when the underlying knowledge base is sufficiently codified and not context-specific, and intellectual property rights are well defined and protected, licensing can work well.

For instance, as we extensively discuss in our book, there exists a very large market for chemical processes and engineering services. The development of chemical engineering played an important role in developing more general and abstract ways of conceptualising chemical processes. As well, patents are thought to work better in chemicals than in other industries. In addition, many processes, especially in petrochemicals, are designed around a specific variety of catalyst which can be kept proprietary because of the difficulty of imitation from sim- 
ple structural analysis alone. The licensor can therefore use the catalyst as a credible hostage: failure by the licensee to respect the initial agreement can trigger a cutoff in the supply of the catalyst.

In a recent paper, Teece (1998) recognises that the formation of markets for technology might change this view. He notes that the unbundling of intellectual property from products generates a new environment for knowledge management where the focus is on how to capture value from knowledge assets, even though he warns that "... becoming a pure licensing company not directly involved in the production market and increasingly remote from the manufacture and design of the product itself can be a risky strategy ..." (see Grindley and Teece 1997). Since risk is sometimes worth the additional reward, the innovator now has the option to balance her ability to extract value from the asset by embodying it in products and services, against the transaction costs involved in trading the technology. In this respect, licensing is an option, not mutually exclusive with self-production. Hence, with a market for technology, a firm needs to recognise what its core, non-tradable and tradable competencies are. Having done so, it can decide whether a given discovery or technological competency is to be exploited in-house or through licensing. In many instances, firms might possess some "noncore" technologies (in some cases, of very substantial value) which can be profitably licensed.

The decision on whether to exploit the technology in-house or not depends on a number of factors. First and foremost, it depends on the distribution of complementary assets. If the firm has superior access to the complementary assets compared to its rivals, in-house exploitation is clearly an attractive strategy. Conversely, if the firm lacks the complementary assets, it may consider selling or licensing the technology. An important special case arises when the technology in question is generic in terms of its application, such as the case of a general purpose technology. In this case, only an extraordinarily large and well-diversified firm will be able to satisfactorily exploit the technology in-house. Otherwise, it is far more likely that the relevant complementary assets will be more broadly distributed, so that licensing the technology would yield higher returns.
The foregoing highlights the importance of the transaction costs involved in the markets for different types of assets. If the transaction costs of acquiring complementary assets such as production and marketing capabilities are lower than the transaction costs involved in selling or licensing the technology, an innovator lacking the complementary capabilities may nonetheless choose to exploit its technology inhouse. In fact, there are many factors that affect transaction costs for technology exchange. Foremost among them are well defined and enforced property rights. Property rights are easier to define and enforce, and transaction costs for technology licensing contracts are lower when the knowledge is articulable (Winter 1987), and can be represented in terms of general and abstract categories (Arora and Gambardella 1994). Such representations reduce the context dependence of the technology, freeing it up to be used more generally and reducing the cognitive barriers to technology transfer (see also Von Hippel 1994).

Difficulty in valuation can significantly increase transaction costs. Accurate valuation is particularly important in cases where the firm lacks downstream assets to commercialise the technology. Current accounting practices and norms, derived as they are from times where measuring tangible and material assets was their crucial task, have to be modified in order for technology markets to flourish.

What is less well understood is the role that technology markets themselves can play in improving the accounting for intangible technological assets. A market for technology improves the accuracy of any valuation attempt. It does so in the most obvious way, by providing an objective measure of the value, if the asset has been traded in the past, or if similar assets have been traded. Needless to say, technology is highly differentiated, and its "price" is likely to reflect factors that are idiosyncratic to the buyer and the seller. Thus, any monetary measure is likely to be imperfect. That said, such problems are not unique to the measurement of the value of technology. A flourishing market for paintings by Old Masters, for instance, shows that product differentiation and idiosyncratic sources of value do not preclude the existence of a reasonably well-functioning market. 
Moreover, when investing in $\mathrm{R} \& \mathrm{D}$, firms are implicitly making such measurements, as do investors when they value the firms in capital markets. Markets for technology allow for the possibility of valuing the contribution of technology separately from the value of other valuable assets the firm may possess. In turn, such valuation may enable firms to specialise in developing technology without necessarily having to acquire downstream capabilities.

In addition to transaction costs, the decision about in-house exploitation also depends on the extent of competition in the different markets in the "value chain" of innovation. For instance, the innovator may face much greater competition in the product market than in the market for technology. In this case, the returns from in-house exploitation are likely to be small, limited by the ability of the innovator to increase its sales and gain market share, typically a slow process. The innovator may face much less competition in the technology market, and may be able to extract much higher returns there. These considerations led Qualcomm to exit from producing handsets embodying its CDMA technology and focus on technology licensing. In the early 1990s, Qualcomm introduced a wireless telephone technology, based on CDMA technology (Code Division Multiple Access), which was markedly superior to the existing technology. It embodied this technology into cellular phones (handsets) and grew rapidly, with a turnover of $\$ 4$ billion, and a net income of more than \$200 million in 1999. However Qualcomm has decided to drastically refashion its business. Citing falling margins in the CDMA handset operations, it divested itself of manufacturing and focused on generating and licensing its CDMA technology. On an annualised basis, Qualcomm earned nearly $\$ 400$ million in licensing and royalty in 1999, which is slightly more than what Qualcomm spent on $R \& D$ in the same year.

\section{Markets for technology and international investments}

Not only are markets for technology important for the generation and the diffusion of technology within firms, well-functioning markets for technology strongly promote the diffusion of technology across countries. Markets for technology promote division of labour and the development of specialised technology suppliers. Once a technology is developed, these technology suppliers can sell it in other countries at a cost that is smaller than the cost of developing the technology in the first place. In this way, follower countries benefit from the fact that an invention, a new technology, or a new design, has already been invented elsewhere, and therefore the cost of making that invention has already been incurred in the originating country.

The chemical processing industry provides an ideal example showing that the development of an upstream industry of specialised technology suppliers improves access, lowers investment costs, and reduces barriers to entry in the dowstream industry, with beneficial effects on the aggregate investment in the latter. The story is that beginning in the 1930 s and continuing into the 1960s, the modern chemical industry in the developed countries (henceforth "First World") grew rapidly. This stimulated the growth of firms that specialised in the design and engineering of the chemical processes, the so-called specialised engineering firms or SEFs. In the 1970s, and especially in the 1980s, as a modern chemical industry emerged in the less developed countries (henceforth LDCs), it benefited from the presence of the SEFs which turned to sell their technologies to the chemical producers in these countries as well. Simply put, the growth of the chemical industry in the first world created an upstream sector, which later spurred the growth of the chemical industry in the developing countries. The important point is that the LDCs benefited from the fact that the (fixed) cost of creating the SEF industry had already been incurred in the First World.

Figure 1 summarises the effects that we want to highlight here. First, the growth of the First World market for a given chemical process encourages the rise of engineering firms specialised in the design of chemical plants for that process. This is the classical effect of the size of the market on the vertical division of labour in an industry. As Smith (1776) and Stigler (1951) noted, when markets grow there are activities that are more effectively performed by specialist companies (suppliers). The latter can serve a market that is larger than the market 
(and hence the size of activities) of the individual downstream firms. This makes the suppliers more efficient because of their greater potential specialisation. By purchasing the input from the more efficient suppliers, the downstream industries benefit from the fact that they acquire the input at lower costs than if the individual companies had to produce it by themselves.

The second effect is from the SEFs in the first world to the size of the developing country market. To understand this effect, suppose that First World SEFs could not supply the LDCs. Then, apart from relying on multinationals, LDC firms would have to provide the services themselves or rely on any domestic SEFs that may exist. In either case, LDC firms would face very high costs. As a result, there will be fewer investments in chemical plants. Given the high transportation costs for many chemical products, this would imply slower growth of chemicals, and of industrial activity more generally.

This simple story relies on the assumption that the critical input, technology, is easily "tradable" across countries. Clearly, applying what one has learnt in one place in another is not always easy, and technology transfer is certainly not costless. Such costs are likely to depend on the very nature of the knowledge embodied in the technology, with tacit and less articulated knowledge being more difficult to transfer, but also on the "absorptive capacity" of the recipient firm (Cohen and Levinthal 1989). However, the important point is that the transfer cost be substantially smaller than the cost of developing the technology in the first place. It is in this sense that the fixed cost of developing or inventing the technology is paid by the industries or countries that emerge earlier (in our case the chemical industries of the First World), while the industries or countries that come later (the chemical industries of the LDCs) pay only the additional cost of adapting the technology to their specific needs and uses rather than the costs of inventing the basic principles in the first place.

In fact, we have to make an important qualification here. We are not saying that with the SEFs the firms in the LDCs face low costs of developing chemical plants, let alone that their costs are lower than those faced by the chemical companies in the First World, or by the multinationals. The cost of setting up a chemical plant by a company from a developing country may well be quite high, even when there are the SEFs. But our point is that with the SEFs it is smaller than if there were no SEFs. In turn, this means that more investments by these firms will take place than if there were no First World SEFs acting as vectors of the process technologies.

In our book, we provide quantitative estimates of the importance of a division of labour in the chemical industry, using data on nearly 140 leading chemical technologies. Our empirical analysis shows that investments in chemical plants in the LDCs are greater the greater the number of technology suppliers (SEFs) that operate in the First World. Moreover, the effect of the SEFs is greater for chemical firms from the developing countries than for the multinational firms investing in the LDCs. This is because the latter firms have greater internal technological capabilities. Hence, for them, the presence of the SEFs is relatively less important.

To get a sense of the order of magnitude of the impact of an upstream sector of technology suppliers on the total investment of the downstream market, we estimated the effect of one additional SEF in a typical process market on the expected total dollar value of investment in the LDCs in that process market. We found that an additional SEF would increase investment by about $\$ 3$ million per year per country. For all 38 LDCs in our sample, the increase in investment in a typical process was of the order of $\$ 114$ million over a 10-year period during 1980-1990. Most of our markets already had more than 5 or 6 SEFs; hence, the effect of an extra SEF was not that big. However, simple simulation from our estimations showed that the effect of having one extra SEF in a market with no SEFs or just one, was rather sizable. The "value" of the SEFs is, as one might have expected, higher when there are fewer of them rather than in markets where there are already quite a few technology suppliers.

In a somewhat different context, one might have conceptualised the phenomenon discussed here as international technology transfer. Undoubtedly, the SEFs are important sources of chemical technology, but many large chemical firms also transfer technology overseas. However, chemical producers have to tradeoff 
the gains from selling technology against the loss in actual or potential revenues from selling the downstream products. On the other hand, the SEFs provide the technologies with few strings attached, and will sell their technologies and expertise to all. In so doing, they have truly helped create a market for technology, from which many developing countries have benefited. Thus, in addition to the classical gains from productivity improvements, specialisation and division of labour can have other benefits for industrial and economic growth that are sometimes overlooked.

Indeed, the fact that opportunities can be transferred from the early movers to the late comers is by no means confined to the case of the SEFs. In a seminal paper, Rosenberg (1976) described how automobile producers benefited from the technologies and tools developed by the machine tool suppliers for the bicycle makers in the nineteenth century. At a later stage, these machine tool producers also helped develop manufacturing industries outside the US. Similarly, the textile machine suppliers of Manchester promoted the diffusion of textile technology to Japan, India, and China, and even today the supply of textile machines by the Italian machine tool producers to textile firms in the LDCs is said to increase the competitiveness of these firms against the very same Italian textile manufacturers in their LDC markets.

\section{"Global" markets for technologies and national policies}

Markets for technology, like other markets, are becoming global. In some ways, this is only to be expected, given the reduced "transport" costs and greater appreciation by even otherwise protectionist governments of the benefits of technology. Rapid advances in communications, the Internet being only the most recent, have only hastened the process of globalisation.

At the same time, it is natural that these markets are far more likely to arise in large and technologically and economically advanced regions, not developing countries. But this also means that the latter need not focus on developing such markets. Instead, they can focus on developing institutions that will enable their firms to participate more effectively in them. The example of the Western European chemical industry in the years after World War II is a case in point. Prior to the war, the industry was technologically far ahead of its US counterpart. The disruption due to the war and the rise of the petrochemical industry, and the associated process technologies in the US, ought to have provided the US chemical industry with a decisive advantage over its European rivals, whose expertise lay in coal-based processes. Yet, in a period of a few years, the German, British, and French chemical industries had largely switched over to petroleum and natural gas as basic inputs. The availability of US-developed refining and chemical engineering expertise made this switch possible. Further, the SEFs played an important role in integrating and supplying technology to European customers. In the 1960s, the SEFs played a similar role in Japan. Japanese industrial policy, which tended to restrict access to the Japanese market for foreign firms, was far more receptive to foreign technology imports. Indeed, the policy focus in this context was in creating the ability to absorb and adapt foreign technology.

The point is simple and well known: global markets tend to circumscribe the role of policy in affecting market outcomes. For smaller countries like the individual European countries or less-developed countries, the impact of their own policies, if they are not coordinated with those of other countries, is likely to be small. For example, policies of smaller countries to develop standards or other types of supporting institutions are unlikely to induce the development of technology markets on a substantial scale. Similarly, strengthening or weakening intellectual property rights will probably have little effect on the global market for technology, although this may affect the extent to which technology flows into their country.

Policies for encouraging, coordinating or controlling the markets for technology will be most effective when they are developed by large countries (e.g., the US), or by sets of countries (e.g., the European Union). Such policies require coordination among countries and supernational interventions in international policy settings. But it is precisely at this super-national level that policy decisions are harder to make 
because of the many conflicting interests involved, and the lack of strong enforcement mechanisms. And this is why policies developed by a large country like the US (e.g., in intellectual property rights or the development of standards) can have a strong impact on the world development of markets for technology. Likewise, the European Union can play a significant role, especially if it can harmonise the policies of the individual member states, and avoid the adoption of different rules and standards by individual member states.

For most other countries, the key policy question may be how to take advantage of the growth in technology trade world-wide. This will require encouraging the effective use of existing technologies, rather than the creation of new ones. As well, policies aimed at monitoring international technological developments increase in importance, as do institutions for enhancing the efficiency of contracts and reducing search costs. In this view, countries may increase their emphasis on the ability to identify and select technology, and develop complementary capabilities.

In sectors where markets for technology are developed, and technology can be traded more effectively, countries or regions should specialise according to comparative advantages. This does not imply that countries should cease to invest in research and development. Rather, it implies that they should be more selective in terms of the sectors and types of activities on which they focus, at least in the short-tomedium run.

It is well known that $R \& D$ and patenting is concentrated in the wealthier countries. In particular, the US and Western Europe have a head start in terms of basic research and developing "generic" technologies like semiconductors and genetics. Their advantage lies not only in being the first movers, but also in the broader industrial base over which they can apply these findings. These advantages are less salient when technologies and products need to be adapted for local uses and needs. If one accepts that companies or industries located "near" users have an advantage when it comes to communicating with their markets and acquiring the relevant information for adapting the technologies, firms in other parts of the world could seize this niche. Thus, even if the production of more basic technologies is concentrated, other regions can access these technologies and exploit their own proximity to users or their comparative advantage in developing complementary technologies, as long as markets for technology work well. ${ }^{5}$

These recommendations are not new and in some quarters, are viewed as a prescription for perpetual technological "backwardness". Some countries may resist such an international division of labour in technology production and adaptation. The reasons may range from national pride to the willingness to control strategic technologies. Thus, some form of "notinvented-here" syndrome, at the country-level, is likely to operate. Whether justified or not, it is important to know that where they exist, markets for technology increase the opportunity cost of such an attitude. Simply put, if others have already paid the fixed cost of developing technology, and competition among sellers implies that the price of the technology is related to the marginal cost of technology transfer, a strategy of developing the technology inhouse and incurring the fixed cost all over again must provide some additional benefits over mere ownership of the technology. There is little point in national policies aimed at "reinventing the wheel" except where such reinvention is a part of the process of building "absorptive capacity" or as a part of a long-run strategy to develop international technological leadership.

Second, in a dynamic setting the international division of labour, with implied specialisation in technology production and adaptation, means that countries specialising in the latter need not give up the possibility of becoming technology producers, at least in some well-defined areas. For example, by starting with a policy of developing technologies complementary to those developed by some leading areas or regions, the local firms and industries may gradually learn about the basic technology as well, possibly becoming the producers of some key technologies (see also Rosenberg and Steinmueller 1988). The Indian software industry, for instance, started as a lowend supplier of software components to the major software companies, especially in the US. There are signs that this strategy may gradually bring at least some of these companies to develop more complex product development 
activities (Arora et al. 2001a). A similar argument can be made for the Irish software companies, which seem to have improved their ability to produce new software products in some niches of the market (Arora et al. 2001b). In short, in a dynamic setting, the pattern of specialisation is not immutable. With luck and hard work, the advantages of specialisation in lower-end technological activities (adaptation) could even become the springboard for a move up the value chain. Learning through systematic interactions with users and the technology producers of more advanced countries may be critical for this process to occur.

Indeed, some countries, like Russia and Israel and to a lesser extent, India, have relatively well-developed scientific and engineering infrastructures. However, they lack the market size and the complementary technological and economic infrastructure that could best exploit their scientific and engineering infrastructure. In this respect, they are similar to specialised technology suppliers. A well-developed and globalised market for technology will enable firms from these countries to derive more value from their investments in science and engineering by supplying technology to those able to develop and commercialise it more effectively. Here too, one may encounter opposition from those who would see this as "giving away the store". Once again, our objective is not to advocate specific policies, for the appropriate policy will depend on the specifics of the situation, but to highlight the option that markets for technology embody.

\section{Conclusions}

This article, and the more extended line of research from which it was drawn, has attempted to answer questions such as, under what conditions will technology resemble a tradable asset, and, if it does, what will be the consequences for the generation and use of new technologies, for the diffusion of technology, and for public policy and business strategy? In trying to answer these questions, we have confronted a variety of challenges. Markets for technology are not easy to define. Technologies often change hands through the capital or final goods in which they are embodied. While our focus is on the sales of technologies disembodied from physical goods, embodying or disembodying the technology may be the outcome of deliberate choice. Moreover, it is difficult to make the distinction between knowledge and technology.

A similar qualification applies to what we consider to be a novel concept we have developed here, namely the division of innovative labour. In many respects, the distinction between the traditional division of labour and the division of innovative labour is not straightforward. But although there are important reasons to distinguish between the two, there are important commonalities as well: the properties and implications (e.g., for economic growth) of vertical specialisation can extend beyond the case of the manufactured goods to specialisation in technology and the innovation process. Thus, the division of innovative labour yields the classic advantages of specialisation. For example, in many leading high-tech industries today smaller technology suppliers show a comparative advantage in creating new ideas and technologies and the larger companies exhibit a comparative advantage in developing and scaling up these technologies, as well as in manufacturing and marketing. Moreover, specialised technology suppliers can be critical in generalising and developing the innovation for broad use and in diffusing the innovation, as the specialised engineering firms (the SEFs) have done in the chemical processing industries for many years, including their role in fostering market-mediated mechanisms for technology transfer towards the LDCs, as we have tried to highlight in this article. Particularly, the SEFs have shown how the division of innovative labour in an industry can lower entry barriers for later entrants. Through a division of labour, the growth of the market in one region can create technology specialists that stimulate growth in other regions.

At the same time, as we discussed in our final section, the globalisation of markets for technology entails new challenges for governments. In particular, we have noted that like any global market, markets for technology too imply a reduced capability of national policies to fully govern them. Moreover, one implication is that especially in follower countries, benefits can arise from a policy encouraging national 
players to buy technologies in such markets, rather than attempting to develop them internally. We are aware of the fact that there could be drawbacks to this strategy. For example, it has been argued that internal investments in technology are important for enhancing local learning capabilities. We simply noted that the advantages of these strategies have to be compared with the difference in costs between the internal development of technologies and the cost of adapting technologies available from international producers. Our story of the specialised engineering firms in the chemical processing industries have indeed shown that a market-mediated division of innovative labour has been a powerful instrument for technology diffusion, and for the growth of the downstream industries in the recipient countries.

\section{Notes}

1. Transactions in technology can also occur through mergers and acquisitions, and through the mobility of people. However, we shall ignore these cases here.

2. A study by the British Technology Group (BTG 1998) has concluded that most large firms in the industrialised countries have unused technologies that they have not licensed in the past but would like to do so. This points to the under-development, if not absence, of a market for technology.

Supporting evidence comes from an estimate by the European Union that, in Europe, 20 billion dollars are spent every year to develop innovations and technologies that have already been developed elsewhere. (See www.europeanpatent-office.org/patinfopro/ index.htm.)

3. In this paper we use billion to mean "thousand million" (US usage).

4. In our book, we discuss in greater detail the nature and the extent of the markets for technology in some of these leading high-tech industries.

5. The experience of Reliance Petroleum is relevant. Reliance Petroleum is part of a large Indian conglomerate, the Reliance Group, that originated in the textile industry and then integrated backwards into intermediates (purified terephthalic acid for polyesters), and then into the production of basic feedstock and refining. Reliance engaged Bechtel and several other very large contractors and successfully built the world's largest "grassroots" refinery, accounting for $25 \%$ of India's refining capacity, and downstream plants, in Gujrat, India. This facility came in 6 months ahead of schedule and under budget. Clearly, although Reliance has invested in chemical engineering capabilities, more critical to its commercial success are the ability to identify sources of technology and manage these. The Reliance experience, of entering the oil refinery business with no capacity for designing or constructing such a facility, suggests that much technology can be acquired through the marketplace by firms that have the appropriate, in-house managerial skills.

\section{References}

Arora, A. and Gambardella, A. 1994. "The Changing Technology of Technical Change: General and Abstract Knowledge and the Division of Innovative Labour", Research Policy 23, 523-532.

Arora, A., Arunachalam, V. S., Asundi, J. and Fernandes, R. 2001. "The Indian Software Industry: Structure and Prospects", Research Policy, 30(8), 1267-1288.

Arora, A., Fosfuri, A. and Gambardella, A. 2001a. Markets for Technology: Economics of
Innovation and Corporate Strategy, Cambridge, MA: MIT Press.

Arora, A., Gambardella, A. and Torrisi, S. 2001b. "Human Capital, International Linkages and Growth: The Software Industry in India and Ireland." Paper Presented at the American Economic Association Meeting, New Orleans, Jan. 4-8.

BARNEY, J. B. 1991. "Firms

Resources and Sustained

Competitive Advantage", Journal of

Management 17, 99-120.
Chandler, A. 1990. Scale and Scope: The Dynamics of Industrial Capitalism, Cambridge, MA: The Belknap Press of Harvard University Press.

Cohen, W. and Levinthal, D. 1989. "Innovation and Learning: The Two Faces of R\&D", Economic Journal 99, 569-596.

Grindley, P. C. and Teece, D. J. 1997. "Licensing and CrossLicensing in Semiconductors and Electronics", California Management Review 39(2), 8-41. 
Lamoreaux, N. and Sokoloff, K. 1997. "Location and Technological Change in the American Glass Industry during the Late Nineteenth and Early Twentieth Centuries", NBER WP \#5938. Cambridge, MA

Lamoreaux, N. and SoKoloff, K. 1999. "Inventors, Firms, and the Market for Technology: US Manufacturing in the Late Nineteenth Century", in N. Lamoreaux, D. Raff and P. Temin (eds.) Learning by Firms, Organizations, and Nations, University of Chicago Press.

Nelson, R. R. 1959. “The Simple Economics of Basic Scientific Research", Journal of Political Economy 67(2), 297-306.

Rosenberg, N. 1976. Perspectives on Technology, Cambridge: Cambridge University Press.
RosenberG, N. and Steinmueller, E. 1988. "Why Are Americans Such Poor Imitators?", American Economic Review Papers and Proceedings 78(2), 229-234.

Sмiтh, A. 1776. The Wealth of Nations (1983 Edition), Harmondsworth, UK: Penguin Papers.

Stigler, G. 1951. "The Division of Labor is Limited by the Extent of the Market", Journal of Political Economy 59, 185-193.

Teece, D. J. 1986. "Profiting from Technological Innovation", Research Policy 15(6), 285-305.

Teece, D. J. 1998. "Capturing Value from Knowledge Assets: The New Economy, Markets for Know-
How, and Intangible Assets", California Management Review 40(3), 55-79.

US Department of Justice 1995. Antitrust Guidelines for the Licensing of IP, Washington, DC:

US Dept. of Justice and the Federal Trade Commission.

Von Hippel, E. 1994. "Sticky Information and the Locus of Problem Solving: Implications for Innovation", Management Science 40(4), 429-439.

WinTER, S. 1987. "Knowledge and Competence as Strategic Assets.” In D. J. Teece (ed.) The Competitive Challenge: Strategies for Industrial Innovation and Renewal, New York: Harper and Row. 